\title{
NMDA receptors are expressed by small-cell lung cancer and are potential targets for effective treatment
}

This article was published in the following Dove Press journal:

Clinical Pharmacology:Advances and Applications

31 March 2010

Number of times this article has been viewed

\author{
William G North' \\ Guohong Gao' \\ Amy Jensen' \\ Vincent A Memoli ${ }^{2}$ \\ Jinlin $\mathrm{Du}{ }^{\prime}$ \\ 'Departments of Physiology and \\ 2Pathology, Dartmouth Medical \\ School, Lebanon, NH, USA
}

Correspondence:William G North Department of Physiology, Dartmouth Medical School, I Medical Center Drive, Lebanon, NH 03756, USA

$\mathrm{Tel}+\mathrm{I} 603650-7736$

Fax + I $603650-6130$

Email william.g.north@dartmouth.edu
Abstract: We previously showed that functional N-methyl-D-aspartate (NMDA) receptors are expressed by human neuroblastoma cells. In this study we demonstrate functional NMDAR1 and NMDAR2 receptors are expressed by small-cell lung cancer (SCLC) classical cell lines NCI H146, NCI H345, and DMS 53, by variant cell line NCI H82, and by most SCLC tumors, and that these receptors are important for the growth of human SCLC tumor xenografts in mice. Reverse transcription-polymerase chain reaction demonstrated mRNA for both receptors, with sequences identical to those for human mRNAs, are expressed in all four cell lines, and these generated proteins of the expected sizes 120 and $170 \mathrm{kDa}$. Cell viability tests showed cell growth was significantly $(P<0.0001)$ impaired by NMDAR1 antagonists MK-801 and memantine. Ifenprodil and Ro25-6981, NMDAR2B antagonists at the polyamine site, also significantly $(P<$ 0.001 ) inhibited the growth/survival of these cells. Alternatively, the glycine-binding antagonist, L701, 324, increased viability to $140 \%$ and $120 \%$ in NCI H345 and NCI H82 cells after 48 hours of incubation. Immunohistochemistry of SCLC tumors with our polyclonal antibodies gave specific positive staining for the NMDAR1 receptor in 8 of 10 tissues examined. Small amounts of these same antibodies significantly reduced the growth of NCI-H345 cells up to $25 \%$ ( $P<0.001)$. When NCI H345 cells were grown as tumor xenografts in mice, the growth of these tumors was reduced by $60 \%(P<0.001)$ by treatments with MK-801 over five days. All of these data point to active NMDAR receptors possibly having an important influence on SCLC growth and survival.

Keywords: NMDA, receptors, small-cell lung cancer, inhibition, treatment

\section{Introduction}

There are about 42,000 new cases of small-cell lung cancer (SCLC) in the United States each year. Present treatments for patients with SCLC generally involve them having high-dose combination chemotherapy with or without radiation therapy. ${ }^{1-6}$ Although there is a high initial response rate to these treatments, and long-term survival in up to $10 \%$ of all cases, ${ }^{1,6-10}$ average life expectancy is increased by only $8-15$ months. While about $80 \%$ of these newly diagnosed SCLC patients respond to chemotherapy, remission generally lasts only 3-6 months. Unfortunately, there is no effective therapy to treat recurrent disease because it is resistant to current treatment, and there is also considerable toxicity associated with current chemotherapies. SCLC is generally regarded a neuroendocrine tumor and a number of peptides associated with central neurons are expressed and release by this cancer. In this study we examine the presence and possible importance of NMDAR1 and NMDAR2 receptors in smallcell lung cancer. 
N-methyl-D-aspartate (NMDA) receptors types 1 and 2 together constitute an important calcium channel for neurons. This channel is activated by the natural ligands glycine and glutamate (NMDAR1) and glutamate (NMDAR2). The proper functioning of these receptors gives rise to stimulatory impulses between neurons and seems to be responsible for long-term potentiation, an essential ingredient of short-term memory consolidation in hippocampal and neo-cortical regions of the brain. ${ }^{11}$ NMDA receptors are also known to activate growth promoting cascades within cells, such as the MAP kinase and ERK pathways, leading to proliferation of some non-neuronal cells. ${ }^{12}$ Alternatively, overstimulation of NMDA receptors can lead to cell death through influx of excessive calcium and apoptosis, a destructive process that has been proposed as a factor involved in a number of neurodegenerative diseases, such as Alzheimer's disease. ${ }^{13,14}$ Recently, the NMDAR1 receptor antagonist memantine has been successfully introduced for therapy in the treatment of Alzheimer's disease. ${ }^{14,15}$ Memantine in particular appears to selectively target overstimulated open NMDA channels, have limited side-effects, and significantly slow loss in cognition. ${ }^{14-16}$ This same drug is also being considered for the treatment of other neurodegenerative diseases, such as Parkinson's disease, because of the improvements of motor behavior it produces in MPTP-treated mice, a laboratory model for this disease. ${ }^{17}$ NMDAR receptors were earlier found by us to have similar roles in the LA-N-2 human neuroblastoma cell line. ${ }^{13}$ Glutamate activated a calcium channel in these cells and this action was enhanced by the presence of glycine. Treatment with excess glutamate or agonist was found to lead to cell death, and antagonists curtailed cell growth. ${ }^{13}$

\section{Materials and methods}

\section{Cultured cell lines}

The classical human SCLC cell lines NCI-H345, DMS53, NCI-H146, and the variant SCLC cell line, NCI-H82, were obtained from American Type Tissue Culture Collection (ATCC, Rockland, MD, USA). Cells were grown and maintained in Dulbecco medium or RPMI 1640 (Mediatech, Inc, Herndon, VA, USA) supplemented with $10 \%$ fetal bovine serum (Sigma Chemical Co, St Louis, MO, USA) at cell densities of $10^{5}$ to $5 \times 10^{5} / \mathrm{mL}$ in a humidified atmosphere of $5 \% \mathrm{CO}_{2}$ at $37^{\circ} \mathrm{C}$.

\section{Reverse transcription-polymerase chain reaction (RT-PCR)}

RT-PCR was performed to evaluate the expression of NMDAR1 and NMDAR2B transcript in four of the SCLC cell lines (NCI-H345, DMS-53, DMS-146, and NCI-H82). Total RNA was first extracted from cell culture using TRIzol reagent (Invitrogen, Carlsbad, CA, USA) following the manufacturer recommended protocol. The synthesis of the cDNA was performed utilizing an oligo(dT) primer and reverse transcriptase (SuperScriptIII; Invitrogen). The cDNA synthesis was performed following manufacturer's recommendation. The RNA was first denatured at $65^{\circ} \mathrm{C}$ for $5 \mathrm{~min}$ then put on ice for $3 \mathrm{~min}$. Then the reaction mixture was incubated at $50^{\circ} \mathrm{C}$ for $45 \mathrm{~min}$, and $70^{\circ} \mathrm{C}$ for $15 \mathrm{~min}$. The PCR with the Platinum Taq DNA Polymerase (Invitrogen) was performed in a Mastercycler gradient thermocycler (Eppendorf, Westbury, NY, USA). The reaction mixture was subjected to an initial denaturation at $94^{\circ} \mathrm{C}$ for $3 \mathrm{~min}$, followed by 30 cycles comprising a denaturation step at $94^{\circ} \mathrm{C}$ for $45 \mathrm{sec}$, a step for annealing the primers to the template at $56^{\circ} \mathrm{C}$ for $45 \mathrm{sec}$, and an extension step at $72^{\circ} \mathrm{C}$ for $1.0 \mathrm{~min}$. At the completion of the cycling reaction, an additional extension step at $72^{\circ} \mathrm{C}$ for 5 min was performed. NMDAR1 primers used in PCR analysis included forward primer 1, 5'-ATC TAC TCG GAC AAG AGC ATC C-3', corresponding to nucleotide 369 to 417 (Genbank L05666); reverse primer 1, 5'-AGC TCT TTC GCC TCC ATC AG-3', corresponding to compliment nucleotide 658 to 639 ; forward primer 2, 5'-AAG TAT GCG GAT GGG GTG ACT-3' (1002 to 1022), reverse primer 2, 5'-CAA AAG CCG TAG CAA CAC TGA $-3^{\prime}$ (1393 to 1373). NMDAR2B primers included forward primer 1, 5'-TCA AGG ATG CCC ACG AGA AAG -3', corresponding to nucleotide residues 358 to 378 (Genbank NM-000834); reverse primer 1, 5'- GTG GCT TCT TCC TTG TGA CAG -3 (922 to 902); forward primer 2, 5'-CCA AAG AGC ATC ATC ACC C -3' ( 441 to 459); reverse primer 2, 5'-TGT AGC CAT AGC CAG TCA G -3' (972 to 954). These primers were synthesized from Integrated DNA technologies, Inc (Coralville, IA, USA). The PCR products were purified by washing once with an equal volume of chloroform and examined on 2\% agarose gels. DNase-free RNase and RNasefree DNase (Gibco/BRL Carlsbad, CA, USA) were employed in some reactions to validate that the products of PCR did not result from initial DNA contamination.

\section{Cloning and sequencing}

Most sequencing was performed directly on RT-PCR products without cloning. However, in some cases fresh PCR product ( $1 \mu \mathrm{L}, 4-12 \mathrm{ng})$ was cloned into a $\mathrm{pCR}^{\mathrm{TM}}$ vector and transformed in One Shot ${ }^{\mathrm{TM}}$ Competent Cells using a TA Cloning Kit (Invitrogen). Cloned cDNAs were prepared by employing a Wizard Mini-preps DNA purification system (Promega, 
Madison, WI), and positive clones were screened with EcoR1 restriction endonuclease (Gibco/BRL) digestion and evaluation on $2 \%$ agarose gels. At least two positive clones of each PCR product were chosen for double-strand cDNA sequencing with a Taq DyeDeoxy ${ }^{\mathrm{TM}}$ Terminator Cycle Sequencing kit (Applied Biosystems, Foster City, CA, USA). The primers designed for PCR amplifications, as described above, and universal primers (M13 Forward, M13 Reverse and T7) were engaged as sequencing primers. The protocol for DNA sequencing was modified as follows: $97^{\circ} \mathrm{C}$ for $2 \mathrm{~min} ; 25$ cycles at $95^{\circ} \mathrm{C}$ and $30 \mathrm{sec} ; 58^{\circ} \mathrm{C}$ for $1.5 \mathrm{~min}$; and $72^{\circ} \mathrm{C}$ for $1.5 \mathrm{~min}$, with a $72^{\circ} \mathrm{C}$ extension for $10 \mathrm{~min}$. The products were purified $(\times 2)$ by phenol/chloroform extraction and precipitation with 100\% ethanol. Sequencing was performed using a Model 373 DNA Sequencer (Instrument 865; Applied Biosystems) and sequence analysis performed using the BLAST network service.

\section{Western blot analysis}

Cell lysates were prepared by sonication using a RIPA Buffer solution (1\% NP-40, 1\% sodium deoxycholate, 0.1\% SDS, $150 \mathrm{mM} \mathrm{NaCl}, 25 \mathrm{mM}$ Tris/HCl, $\mathrm{pH}$ 7.4) with protease inhibitor (Roche, Indianapolis, IN, USA), the extract centrifuged at $12,000 \times g$, and the supernatant retained. The protein content of these extracts was assessed by differential absorbance measurements at $215 \mathrm{~nm}$ and $225 \mathrm{~nm}$. Aliquots of these lysates representing approximately $100 \mu \mathrm{g}$ of protein were first reduced with 2-mercaptoethanol in a boiling water bath for $5 \mathrm{~min}$, then separated by SDS-PAGE on 12\% gels using Tris/Glycine/SDS buffer (25 mM Tris, $192 \mathrm{mM}$ glycine, $0.1 \% \mathrm{SDS}, \mathrm{pH} 8.3)$. These gels were subjected to a voltage of $50 \mathrm{~V}$ for 10 minutes, followed by a voltage of $75 \mathrm{~V}$ for approx $2 \mathrm{~h}$ at ambient temperature or a voltage of $100 \mathrm{~V}$ for $1 \mathrm{~h}$ at $4^{\circ} \mathrm{C}$. The proteins were transferred onto Immobilon-P polyvinylidene difluoride membrane (Millipore, Bedford, MA, USA) in Tris/glycine/SDS buffer with 20\% methanol, using the MiniProtean 3 system (Bio-Rad, Hercules, CA, USA). The membrane was blocked by drying using a Model 583 Gel Dryer (Bio-Rad) and by incubation with $5 \%$ bovine serum albumin (BSA) or 5\% nonfat milk/0.1\% Tween 20, followed by incubation with primary antibodies. PANN1 is a rabbit polyclonal antiserum produced in this laboratory and directed against an N-terminal segment of NMDAR1 (see below). Antibodies from this antiserum were first isolated by affinity chromatography. Commercially available NMDAR1 antiserum was obtained from Cell Signaling Technology (Beverly, MA, USA), and NMDAR2 antiserum was purchased from Santa Cruz (NMDAe2; Santa Cruz Biochemicals, Santa Cruz, CA, USA). The latter antiserum recognizes all NMDAR2 subunits.
Most Western blotting involved the NMDAR1 antibody from Cell Signaling Technology because this commercial product worked better than our PANN1 antibodies with this procedure, while PANN1 proved to be superior for immunohistochemistry. The blots were visualized using a chemiluminescence method that employed a horseradish peroxidase-labeled goat antirabbit antibody (Pierce, Rockford, IL, USA, or Cell Signaling), a Lumi-Light Western Blotting Substrate (Roche) or SuperSignal West Pico Chemiluminescent Substrate (Pierce), and exposure of X-ray film. They were scanned and evaluated using an AlphaEaseFc Stand Alone Image Machine with PC software (Alpha Innotech, San Leandro, CA, USA). The blots were stripped and incubated with GAPDH (Chemicon Rosemont, IL, USA), or scanned with anti- $\beta$-actin (Sigma), to ensure equal protein loading.

\section{Cell growth/viability assay}

A) Effects of antagonists: Four cultured SCLC cell lines (NCI H82, NCI H146, NCI H345, DMS 53) were employed. Cells were treated with $0.05 \%$ trypsin, washed in PBS/ glycine and plated onto 96 well plates at $10^{4}$ cells/well in medium for 24 hours to provide time for rectifying possible damage to membrane proteins from the trypsinization. The wells were washed and incubated with $\mathrm{PBS} /$ glycine containing albumin $(1.25 \mathrm{mg} / \mathrm{mL})$ in the presence of differing concentrations of NMDA receptor antagonists $(25-800 \mu \mathrm{M})$, and Alamar Blue (1:10 dilution following manufacturer's recommendation). These antagonists comprised memantine and dizocilpine maleate (MK-801) that noncompetitively block NMDAR1 receptors, Ifenprodil and Ro 25-6981 that block NMDAR2B receptors at the polyamine site, and L-701,252 and L701,324 that block NMDAR1 receptors at the glycine site. Fluorescent readings were taken at periods representing 24,48 , and $72 \mathrm{~h}$ of incubation with antagonist using a Synergy HT Multi-Detection Microplate Reader and excitation/emission wavelengths of $530 \mathrm{~nm}$ and $590 \mathrm{~nm}$. Cell viability was evaluated as \% vehicle control at the corresponding incubation time.

B) Effects of anti-NMDAR1 antibodies: Rabbit polyclonal anti-NMDAR1 antibodies (PANN1) were generated by us against an N-terminal extracellular peptide domain (-Met-Ser-Ile-Tyr-Ser-Asp-Lys-Ser-Ile-His-) of the human receptor, in the form of the peptide amide coupled through glutaraldehyde to bovine thyroglobulin as antigen, and use of Fruend's complete and incomplete adjuvant. ${ }^{18,19}$ This peptide domain is represented in that portion of the mRNA message sequenced by RT-PCR (see above). For 
studies on cell proliferation, the IgGs of this antiserum were first isolated by precipitation with $50 \%$ saturated ammonium sulfate, and antibodies were then purified from these immunoglobulins by affinity chromatography using a column comprising the peptide component of the above antigen coupled to Sepharose. ${ }^{20,21}$ Two dilutions (1/10 and $1 / 50$ ) of an affinity purified PANN1 antibody preparation in PBS $/ 0.5 \%$ BSA $(<<375$ fmol Ab and $<<75$ fmol Ab) were incubated with cells in 1640 medium for $24 \mathrm{~h}$ at $37^{\circ} \mathrm{C}$, and cell growth compared with cells treated liquid vehicle using the Alamar Blue procedure described above.

\section{Immunohistochemistry of human tumor tissue}

Immunohistochemical (IHC) staining for human NMDAR1 was performed on formalin-fixed preparations from ten SCLC tumors representing primary, metastatic, and recurrent disease. These preparations were obtained from an archival tissue library of SCLC at the Department of Pathology, Dartmouth-Hitchcock Medical Center. Tissue sections ( $4 \mu \mathrm{m})$ of formalin-treated material were steamed in citrate to recover antigen and then blocked by incubating them with $10 \%$ horse serum. They were then incubated for two hours at ambient temperature with either affinity-purified PANN1 (see above) in $\mathrm{PBS} / 5 \%$ BSA alone, PANN1 in PBS/5\% BSA containing an excess of peptide antigen as negative control, or PBS/5\% BSA. Following washings (x3) in PBS/BSA, tissues were incubated for $1 \mathrm{~h}$ at ambient temperature with biotinylated horse anti-rabbit IgG, washed (x3), then incubated for $1 \mathrm{~h}$ at ambient temperature with streptavidin coupled to peroxidase. Tissues were again washed (x3) and finally reacted with a diaminobenzidine/peroxide mixture and contrasted with hemotoxylin. No effort was made in this study to detect NMDAR2 receptor subunits in SCLC or normal lung by immunohistochemistry.

\section{Treatment of SCLC tumor xenografts in mice}

Human tumor xenografts of SCLC cell line NCI H345 were raised in nu/nu mice by injecting $\sim 2 \times 10^{-7}$ cells subcutaneously along the flank in $200 \mu \mathrm{l}$ complete medium. When tumors of $>0.5 \mathrm{~cm}$ diameter became established, the influence of the NMDAR1 receptor antagonist dizocilpine maleate (MK-801) was then examined on tumor growth measured daily by multiplying depth, width, and length determined using a micrometer. Tumor growth in a control group of animals receiving i.p. PBS vehicle $(\mathrm{n}=4)$ was compared with tumor growth in animals $(\mathrm{n}=4)$ receiving i.p. dizocilpine maleate (MK-801) over 10 days. Animals received an escalating single dose of this NMDAR1 antagonist from $0.1 \mathrm{mg} / \mathrm{kg}$ body weight each day for days $0-2$, then to a single dose of $0.2 \mathrm{mg} / \mathrm{kg}$ body weight each day for days 3-6, then to a single dose of $0.3 \mathrm{mg} / \mathrm{kg}$ body weight each day for days 7-8. Finally two daily doses of $0.3 \mathrm{mg} / \mathrm{kg}$ body weight were given for days $8-10$. This escalating dose range was designed to produce maximal effects without causing adverse behavioral changes as based on the work of others. ${ }^{22,23}$

\section{Statistical evaluations}

Results were analyzed by Analysis of Variance (ANOVA) and the Student-Neuman-Kuels test. Longitudinal growth data was evaluated using repeated measures ANOVA. Significance was determined to be present for $P<0.05$.

\section{Results}

\section{Expression of NMDA receptors by SCLC cultured cells and tumor tissues}

RT-PCR of poly $\left(\mathrm{A}^{+}\right) \mathrm{RNA}$ preparations from all four SCLC cell lines using selected forward and reverse primers, gave, in each case, a single overlapping product of size predicted from the structure of cDNA for human NMDAR1 from brain tissue, and reported earlier by us for human LA-N-2 neuroblastoma cells. ${ }^{13}$ Cloning and nucleotide sequence analysis of these NMDA glutamate receptor RT-PCR products (488 bp and $263 \mathrm{bp}$ ), coding for portions of the extracellular domain, showed them to have exact sequence homology with position 208-695 of the brain and neuroblastoma receptor, and sequence identity in this portion of the NMDAR1 receptor for all four SCLC cell lines. The region in the mRNA examined represents approximately $30 \%$ of the open reading frame for the extracellular $\mathrm{N}$-terminal domain for this receptor subunit. As was found for the mRNA from LA-N-2 cells, there was no evidence for alternate splicing of the message as has been reported by Moriyoshi et $\mathrm{al}^{24}$ for NMDAR1 from rat brain. RT-PCR of poly $\left(\mathrm{A}^{+}\right)$RNA was unaffected by prior treatment of preparations with DNase, and no products were generated when initial treatment with RNase was performed or when reverse transcriptase was omitted from reaction mixtures. Nucleotide sequencing also revealed normal sequences for the two other regions of NMDAR1 mRNA amplified giving predicted RT-PCR products of 300 and 391 base pairs (Figure 1a). In addition, RTPCR of NMDAR2B message provided predicted products of 471 and 564 base pairs (Figure 1b), that upon nucleotide sequencing were shown to have sequences identical to those reported by Hess and coworkers. ${ }^{20}$ There is now a consensus 


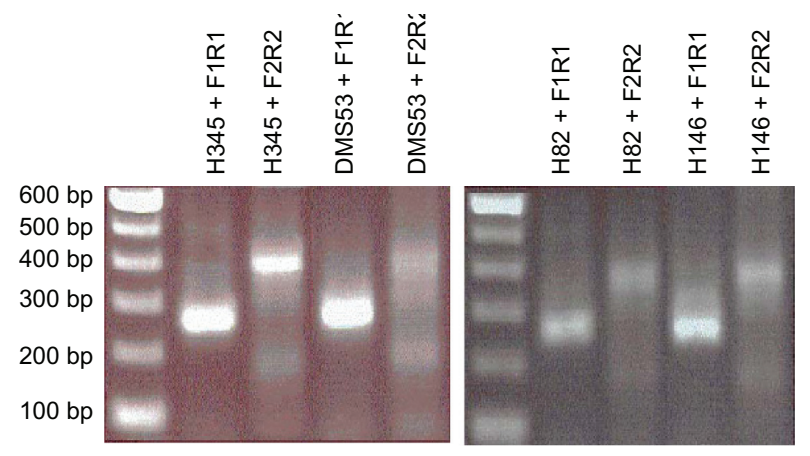

A Expression of NMDAR1 receptors in SCLC cells

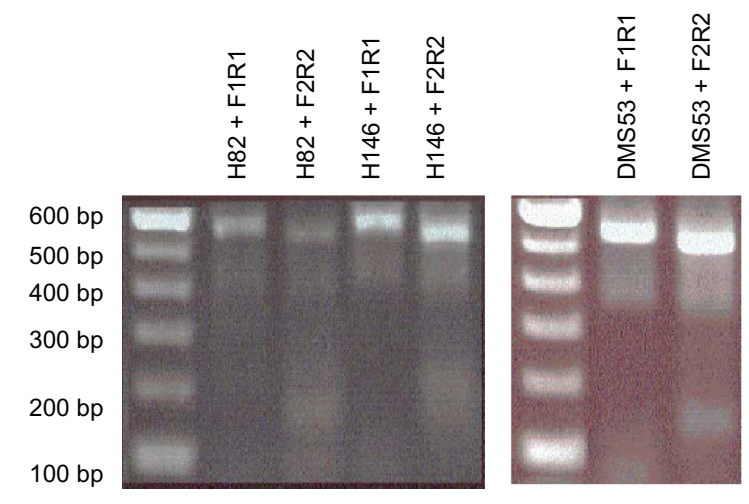

B Expression of NMDAR2 receptors in SCLC cells

Figure I Genes for both NMDARI and NMDAR2B receptors are expressed in cultured small-cell lung cancer cells. A) The expression of NMDARI receptors in the cultured cell lines by RT-PCR using primers designed to amplify different regions of the coding sequence (see text for details). Shown are results obtained for classical cell lines $\mathrm{NCl} \mathrm{H345,} \mathrm{NCl} \mathrm{HI46,} \mathrm{and} \mathrm{DMS} \mathrm{53,} \mathrm{and} \mathrm{variant} \mathrm{cell} \mathrm{line} \mathrm{NCl} \mathrm{H82.} \mathrm{B)} \mathrm{The}$ expression of NMDAR2B receptors by cultured cell lines by RT-PCR using primers designed to amplify different regions of the coding sequence for this receptor (see text for details). Shown are results obtained for classical cell lines NCl 146 and DMS 53 , and variant cell line $\mathrm{NCl} \mathrm{H82}$. Sequence analysis of the products using nested primers indicated normal NMDARI and NMDAR2B messages. Products were separated on $1.5 \%$ agarose gels, which were then stained with ethidium bromide. In each case one band of the expected size was obtained for the amplification product.

that the molecular weight of the NMDAR1 protein subunit is $116 \mathrm{kDa}$, and a major band of approximately this size was displayed for NCI H345, NCI H82, NCI 146, and DMS 53 cells in Western Analysis using both commercial antibod-

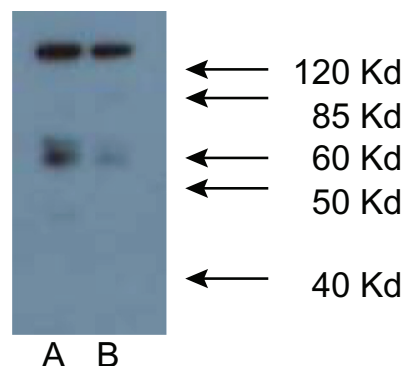

Figure 2 Western analysis of NMDA receptor proteins in $\mathbf{A}) \mathrm{NCl} \mathrm{H345} \mathrm{and}$ B) $\mathrm{NCl} \mathrm{H82} \mathrm{SCLC} \mathrm{cells.} \mathrm{NMDAR} \mathrm{receptor} \mathrm{proteins} \mathrm{are} \mathrm{present} \mathrm{in} \mathrm{SCLC} \mathrm{cancer}$ cell lysates from all four cell lines. Lysates were analyzed by SDS-PAGE using $12.5 \%$ gels and Western blot using our own and commercial antibody preparations recognizing NMDARI proteins. Shown are results obtained for $\mathrm{NCl} \mathrm{H345} \mathrm{A)} \mathrm{and}$ $\mathrm{NCl} \mathrm{H82} \mathrm{B)} \mathrm{cells} \mathrm{with} \mathrm{a} \mathrm{commercial} \mathrm{antibody} \mathrm{against} \mathrm{NMDARI} \mathrm{protein} \mathrm{(Cell} \mathrm{Signaling}$ Corp). Molecular mass markers $(\mathrm{kDa})$ are indicated on the right side of the figure and demonstrate the presence in lysates of a major form protein of $116 \mathrm{kDa}$ and a minor form of $55 \mathrm{kDa}$.

ies and affinity-purified PANN1 antibodies. A second minor band of approximately $55 \mathrm{kDa}$ was also always apparent. This second band could be an N-terminal break-down product of the receptor, because both the commercial antibodies from Cell Signaling and PANN1 are directed against an $\mathrm{N}$-terminal moiety of the protein (Figure 2). Alternatively, the NMDAR2 subunits are $165-180 \mathrm{kDa}$, and a major band of approximately $170 \mathrm{kDa}$ (in addition to bands corresponding to smaller proteins) was displayed in Westerns of all SCLC cell lines by the Santa Cruz NMDAR2e polyclonal antibody (data not shown), indicating that NMDAR2A, B, or C of normal size is expressed by all of the cell lines. Coupled with RT-PCR data, we can infer that SCLC cells express and translate at least the NMDAR2B form of the NMDAR2 receptor.

Immunohistochemical evaluation of SCLC tumor sections with anti-NMDAR1 antibodies gave strong and clear positive staining $(+3$ and +4$)$ for eight of ten tumors (Figure 3), and weak, questionable staining $(+2)$ in the other

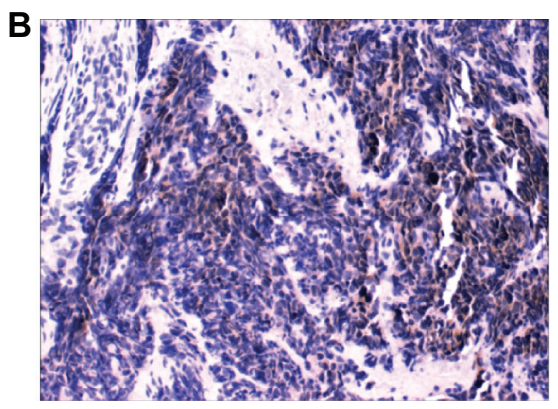

Figure 3 IHC analysis of SCLC tumor: A) Positive staining with polyclonal antibody and B) Negative control with polyclonal antibody + blocking peptides. NMDARI protein is present in small-cell lung tumors. A) Positive $A B C$ immunohistochemical staining in a tissue section of a primary tumor located in the lung of a patient using our polyclonal antibodies that recognize an $\mathrm{N}$-terminal peptide fragment of the receptor. Staining was concentrated at the surface of cancer cells and absent from adjacent normal cells. B) Control 'peptide-negative' $A B C$ immunohistochemical staining in an adjacent section when the polyclonal antibodies were masked by addition of excess peptide antigen (magnification 20x). 

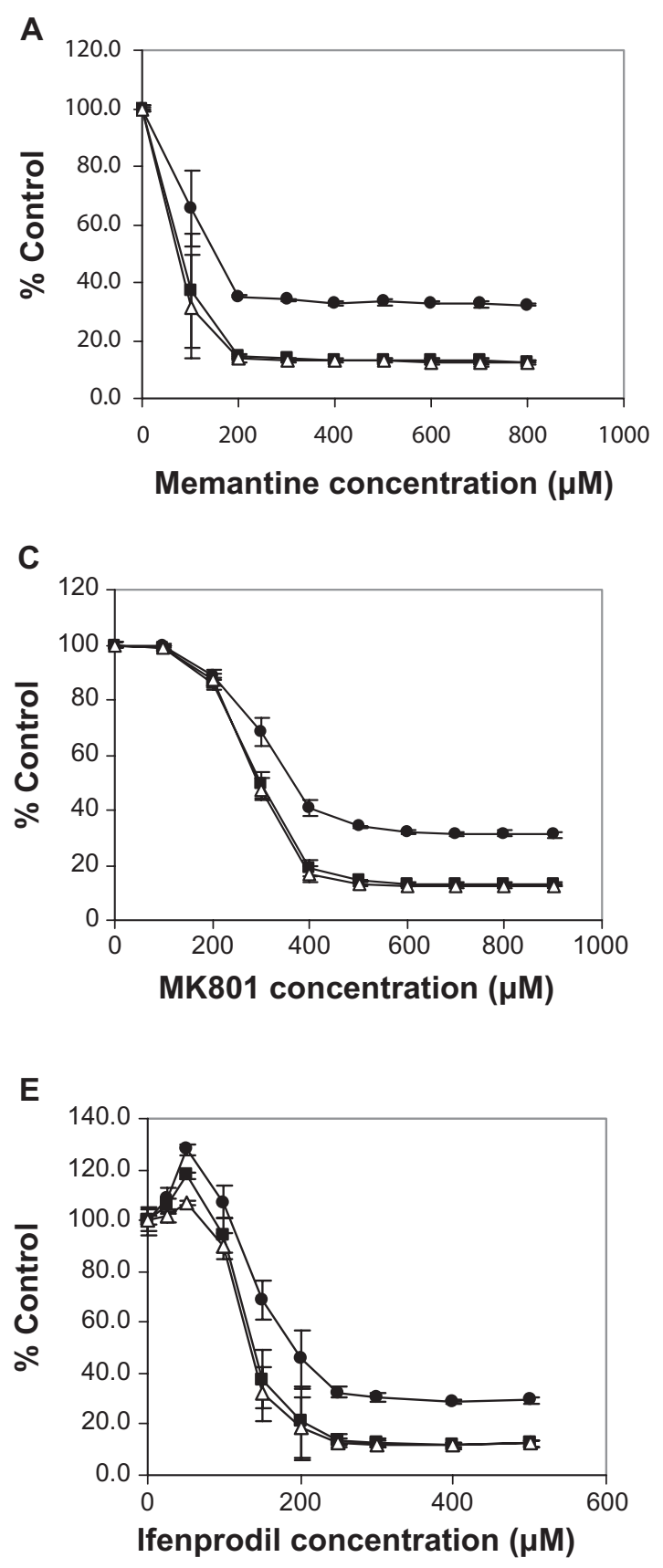
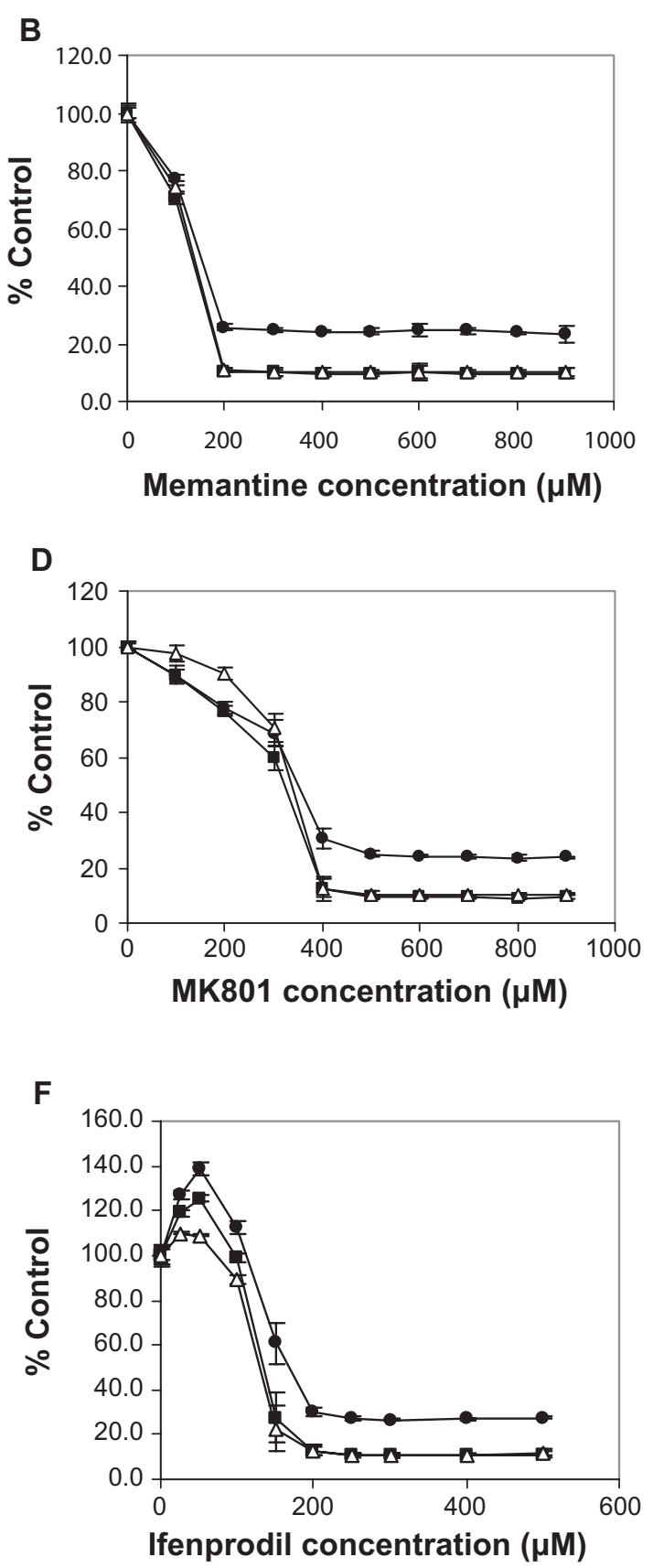

Figure 4 Effects of NMDARI antagonists memantine (A,B) and MK-80I (C,D) and NMDAR2B antagonist Ifenprodil (E,F) on H345 (A,C,E) and H82 cell (B,D,F) proliferation after $24 \mathrm{~h}(\bullet), 48 \mathrm{~h}(\boldsymbol{\bullet})$ and $72 \mathrm{~h}(\Delta)$ of treatment. NMDARI and NMDAR2 receptors appear to be important for proliferation of SCLC culture cell lines. Percentage reduction in cell viability produced in $\mathrm{NCl} \mathrm{H} 345$ classical cells $(\mathbf{A}, \mathbf{C}, \mathbf{E})$ and in $\mathrm{NCl} \mathrm{H} 82$ variant cells $(\mathbf{B}, \mathbf{D}, \mathbf{F})$ by the action of irreversible $\mathrm{NMDARI}$ receptor antagonist Memantine $(\mathrm{a}, \mathrm{b})$, irreversible NMDARI receptor antagonist Dizocilpine Maleate (C,D), and irreversible NMDAR2B receptor antagonist Ifenprodil (E,F) following $24 \mathrm{~h}(\bullet), 48 \mathrm{~h}(\bullet)$ and $72 \mathrm{~h}(\Delta)$ of treatment. Cell viability was reduced to about $10 \%$ of control as assessed using Alamar Blue staining. Reductions in viability were all highly significant $(\mathrm{P}<0.000 \mathrm{I})$ and IC50s were obtained with 80-100 $\mu$ M doses of Memantine, with $200 \mu \mathrm{M}$ doses of Dizocilpine Maleate, and with I 50-200 $\mu$ M doses of Ifenprodil, at 48 and $72 \mathrm{~h}$ of incubation.

two cases examined. All of the 6 cases of metastatic and recurrent disease were among those giving a strong positive reaction. Normal cells in each section did not react with the antibodies. No positive staining of normal lung and liver was apparent with PANN1 anti-NMDAR1 antibodies for the same conditions of IHC, except for Kufper cells in the liver and isolated macrophages in both tissues (data not shown).

\section{NMDA receptor antagonists affect cultured SCLC viability}

Significant effects $(P<0.01)$ on cell viability by different antagonists (reductions to $10 \%$ control or increases to $140 \%$ control) were found at all three incubation times of 24,48 , and $72 \mathrm{~h}$. The changes induced following $48 \mathrm{~h}$ and $72 \mathrm{~h}$ of incubation were similar, and greater than 
those found following $24 \mathrm{~h}$ of incubation. Effects were also different for the different cell lines. Memantine and MK-801 produced dramatic decreases $(P<0.0001)$ in cell viability (Figure $4 \mathrm{a}-\mathrm{d}$ ). For memantine, $\mathrm{IC}_{50} \mathrm{~s}$ at $48 \mathrm{~h}$ were as follows for the each cell line: $80-130 \mu \mathrm{M}$ for NCI-H345 and NCI-H82; $400 \mu \mathrm{M}$ for NCI-H146, and; $800 \mu \mathrm{M}$ for DMS-53. For MK-801, $\mathrm{IC}_{50} \mathrm{~s}$ at $48 \mathrm{~h}$ were as follows: $300 \mu \mathrm{M}$ for NCI-H345 and NCI-H82; $650 \mu \mathrm{M}$ for NCI-H146, and; $>800 \mu \mathrm{M}$ for DMS-53. Both Ifenprodil and Ro 25-6981 also decreased cell viability (Figure $4 \mathrm{e}, \mathrm{f}$ ). For Ifenprodil, $\mathrm{IC}_{50} \mathrm{M}$ at $48 \mathrm{~h}$ for the diffent cell lines were: $\sim 150$ and $\sim 200 \mu \mathrm{M}$ for NCIH345 and NCI-H82 cells; a reduction no greater than $40 \%$ with NCI-H146 cells, and; even smaller decreases than $40 \%$ with DMS-53. The effects of the glycine site binders were examined only with NCI-H345 and NCI-H82 cells. At 48 h, L-701,324 actually produced an increase in cell viability to approximately $140 \%$ and $120 \%$ of control for NCI-H345 and NCI-H82, respectively. While, L-701,252 also produced an increase to approximately $120 \%$ of control for NCI-H345 cells, no clear effects over the concentration range used were found with NCI H-82 cells. Differences between different cell lines probably reflect either, a concentration range of receptor expression, or a differing dependence of the cells on functional NMDARs for growth. However, effects were greatest on the one variant cell line (and one classical cell line) and this variant cell line represents recurrent and drug-resistant disease. It is of interest that preventing glycine from binding to NMDAR1 receptors seems to improve cancer cell survival, although at the concentrations employed, these antagonists might be functioning as agonists.

\section{Anti-NMDARI antibodies affect SCLC cultured cell viability}

When PANN1 (anti-NMDAR1) rabbit polyclonal antibodies as an affinity-purified preparation were administered for $24 \mathrm{~h}$ at 1:50 ( $<<10 \mathrm{ng},<75 \mathrm{fmol}$ antibody) or 1:10 $(<<50 \mathrm{ng},<0.375 \mathrm{fmol}$ antibody) the proliferation of small cell lung cancer NCI H345 cells in culture was significantly $(P<0.001)$ decreased by about $6 \%$ and $25 \%$, respectively, compared with controls (Table 1). These data show an importance of NMDAR1 receptors in proliferation of this SCLC cell line, and suggest they may be important to other cell lines. They demonstrate the availability of the antigenic site on the receptors for antibody binding and that such binding disrupts signaling through these channels. Additionally, they
Table I Anti-NMDARI effects on growth of $\mathrm{NCl} \mathrm{H345}$ cancer cells

\begin{tabular}{ll}
\hline Treatment (24 h) & Fluorescence of alamar blue \\
\hline Control, I:50 & $723.5 \pm 3.8$ \\
AntiNMDARI, I:50 & $678.0 \pm 2.8 * *$ \\
Control, I:I0 & $811.3 \pm 5.5$ \\
AntiNMDARI, I:10 & $617.0 \pm 2.9 * *$ \\
\hline
\end{tabular}

Notes: *Significant at $P<0.001$ compared with control.

imply that increased doses of these or similar antibodies, especially directing cell cytotoxicity in vitro and in vivo, could kill most, or all such cancer cells. The sequence of human NMDAR1 protein used to generate antibodies is identical in the mouse NMDAR1 protein. This means the mouse would be a suitable model to study the effects of anti-NMDAR1s on tumors in vivo.

\section{A receptor antagonist slows tumor development and tumor growth}

The treatment of established tumor xenografts from H-345 cells in nu/nu mice with MK-801 for the doses used produced no noticeable behavioral effects in the animals and had no apparent effect on their well-being as exemplified by body weight in treated animals paralleling that for controls (Figure 5a). However, MK-801 in these same doses produced highly significant $(P<0.001)$ reductions in the rate of tumor growth, to almost $60 \%$ that of controls, over the course of the study (Figure 5b). This effect on growth was evident for even the lowest dose of $0.1 \mathrm{mg} / \mathrm{kg}$ body weight.

\section{Discussion}

The findings presented here for SCLC cell lines and tissues provide strong evidence that NMDA receptors are components of most of these neuroendocrine tumors, regardless of whether the tumor is primary or recurrent disease, and regardless of it being localized or metastatic disease. All four of the SCLC cells in culture, including a variant cell line (NCI H82) that represents recurrent and drug-resistant disease, were shown to express mRNAs for NMDAR1 and NMDAR2B that appears to be the same as that found by others in the human brain, and, in the case of NMDAR1, by us for a human neuroblastoma cell line. ${ }^{13,2}$ Partial sequencing of these messages show sequence identity with messages from these other sources. These mRNAs were shown by Western analysis to give rise to receptor proteins of approximately 


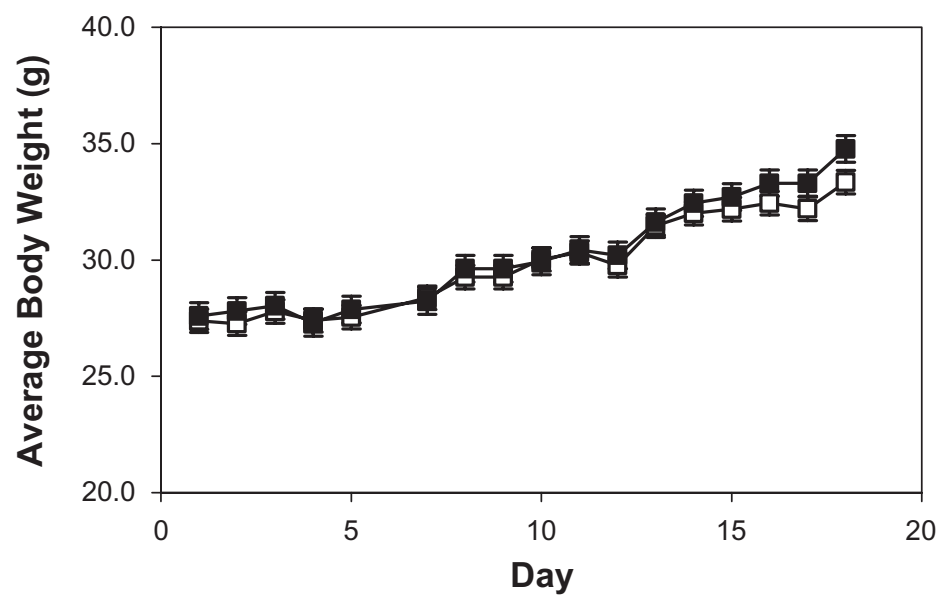

A Average body weights of the control ( $\square$ ) and treated ( $\square$ ) animals before and after treatment.

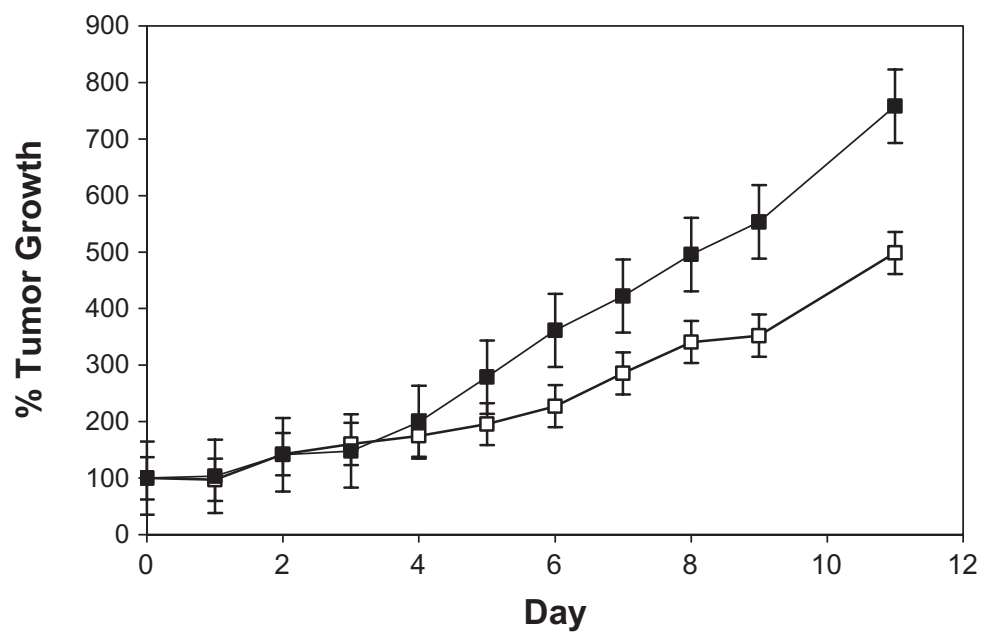

B Inhibition of SCLC H345 tumors in control ( $\square$ ) and treated ( $\square$ ) animals.

Figure 5 NMDARI receptors have an influence on the growth of SCLC tumor xenografts in nu/nu mice. A) Administration of MK-80I in doses up to 0.3 mg/kg twice daily has no impact on the health of nu/nu mice as assessed by body weight over and beyond the treatment period. B) Growth of small-cell tumors from NCl-H345 cells is significantly $(\mathrm{p}<0.000 \mathrm{I})$ reduced by treatment with escalating doses of $\mathrm{MK}-80 \mathrm{I}$ from $0.1 \mathrm{mg} / \mathrm{kg}$ once daily to $0.3 \mathrm{mg} / \mathrm{kg}$ given twice daily as indicated. Tumor volume measured by micrometer was expressed as the product of length $\times$ width $\times$ breadth and was evaluated on a daily basis.

$120 \mathrm{kDa}$ (NMDAR1) and $170 \mathrm{kDa}$ (NMDAR2B), of similar sizes to functional brain receptors. ${ }^{3}$ However, the commercial anti-NMDAR2 antibodies used could not reveal which of the known NMDAR2 sub-types were present on these cells, so it is possible that they represent all or any one of these receptors.

That NMDAR1 receptor proteins of SCLC are functional and important to cell growth is illustrated by the effects of the non-reversible NMDAR1 antagonists memantine and dizocilpine (MK801). Both of these antagonists dramatically reduced cell viability of all of the SCLC cell lines examined. The amounts of MK-801 producing these effects are similar to amounts found to alter neuronal activity in culture ${ }^{21,25}$ and intracellular growth cascades of lung adenocarcinoma cells ${ }^{26}$ and breast cancer cells ${ }^{27}$ in culture. On SCLC cells, memantine seemed to be approximately twice as effective as MK-801 in vitro, despite it having a much lower binding affinity than the latter antagonist. As mentioned above, it has been proposed that unlike MK-801, memantine appears to selectively block overstimulated ("pathological") open channels and have very few side-effects through normally functioning channels. ${ }^{14,15}$ If verified in vivo, we can anticipate memantine would have a selective action on the NMDA receptors of SCLC tumors, particularly recurrent tumors, in patients. In this regard, of special interested were effects on cells of the NCI H82 variant cell line, which represents recurrent and drug-resistant disease. This cell line, together with NCI H345, was the most susceptible of the cell lines examined.

We consider that proof of the principle for the assertion that NMDAR1 receptors are important to SCLC is provided 
by the influence of MK-801 on the growth of tumor xenografts of NCI H345 in nude mice. A substantial reduction in the growth rates of these tumors to approximately $50 \%$ of controls was found at the end of treatment, at doses of antagonist that had no apparent negative influence on the health of animals. The uppermost dose chosen is the same as that used by others to increase the survival time of mice implanted with lung adenocarcinoma cells, ${ }^{26}$ and by us to prevent breast cancer growth. ${ }^{27}$ It is similar to those amounts known to have some influence on behavior in rodents. ${ }^{28-30}$ Such an influence would impose a limitation in the use of small molecules such as MK- 801 because they can readily cross the blood-brain barrier and perhaps disrupt neuronal activities. However, the absence of any adverse effects on animal behavior observed here suggests doses of MK-801 similar to those used could safely aid in the treatment of brain metastases of SCLC. The ideal dose levels of the antagonist and duration of treatment to achieve maximal impact on tumor growth has yet to be determined, as has the influence of other NMDAR1 and NMDAR2 antagonists. Support for our findings is found in the studies of Stepulak et $\mathrm{al}^{26}$ on mouse xenografts of human lung adenocarcinoma and rhabdomyosarcoma. These authors found treatment with MK801 increased the survival time of mice with lung adenocarcinoma and slowed the growth of rhabdomyosarcoma. But, the importance of NMDAR1 receptors to SCLC is further supported by the in vitro effects that antibodies directed against the extracellular domain have on the viability of NCI H345 cells, presented in the current study. Additionally, although preliminary, our use of the same antibodies in IHC demonstrates that NMDAR1 receptors are present on primary and recurrent human SCLC tumors from different anatomical locations. All of these findings raise the possibility of using similar antibodies as targeting agents in patients for directing both diagnosis and future treatments. That such antibody approaches to treatment would not adversely affect individuals is suggested by the work of During and coworkers ${ }^{31}$ who were able to perform safe oral vaccination in animals against NMDAR1 receptors.

NMDAR2 receptor proteins also are functionally important to, at least some, SCLC as illustrated by our findings with antagonists to these receptors. The specific NMDAR2B receptor antagonist Ifenprodil that binds to the polyamine site of these proteins ${ }^{32-34}$ was most effective on the cell lines NCI H345 and NCI H82. Ifenprodil produced large reductions in cell growth of both cell lines that were highly significant $(P<0.001)$ over a concentration range from $150-500 \mu \mathrm{M}$ (Figure 4). However there were trends towards an increase in growth rate in the presence of the lower concentrations of 25 and $50 \mu \mathrm{M}$ antagonist, and no effect with $100 \mu \mathrm{M}$ antagonist.
Like the findings with NMDAR1 receptor antagonists, maximal effects were seen after $48 \mathrm{~h}$ of incubation. These data suggest that antagonists of NMDAR2B could produce large decreases in SCLC tumor growth rates when given in appropriate amounts. In this respect, the doses of Ifenprodil that seem to be well tolerated in animals are higher than those required to generate blood concentrations compatible with those found here to inhibit most tumor cell growth in vitro. ${ }^{35}$ The broader range NMDAR2 receptor antagonist Ro28-6981, that like Ifenprodil binds to the polyamine site, had similar effects on NCI H345, NCI H82, and NCI H146 cells, although no effects were seen on the viability of the DMS 53 cell line. Differences could reflect on the relative amounts and importance of NMDAR 2 sub-types to individual cell lines, and by extrapolation, to individual tumors.

Additional support for NMDAR receptors affecting tumor growth was the observed influence of the two 'glycine' site antagonists used here to impart significant increases in viability to NCI H345 and NCI H82 cells, but not produce measurable effects for the concentrations used on the viability of other cell lines examined. This somewhat puzzling outcome is thought to reflect an agonistic, rather than antagonistic, action of these substances for the concentration range employed in the study.

Our findings demonstrate that NMDA receptors are present on SCLC and are likely agents for maintaining cell growth and viability. This occurrence of these receptors on most SCLC has yet to be substantiated by examining a much larger number of cases. Additionally, the specificity of some of the effects recorded here will need to be established by observing their absence in either, as yet to be identified nonNMDAR- expressing SCLC cells, or cells in which the expression of NMDAR receptors has been 'knocked out'. However, findings already presented here raise the possibility of exploring new approaches for the treatment and diagnosis of most patients with SCLC tumors, particularly those with recurrent disease, that involve manipulation or blockade of these receptors.

\section{Acknowledgments}

The general technical assistance of Alison J North is gratefully acknowledged. The authors are also thankful to Dr Roy Pang of Woomera Therapeutics Inc for his advice with this manuscript. Support for these studies was in part obtained from Public Health Service grant NCI/NIH R21CA122546. The authors report no conflicts of interest in this work

\section{References}

1. Johnson BE, Grayson J, Makuch RW, et al. Ten-year survival of patients with small cell lung cancer treated with a combination chemotherapy with or without irradiation. J Clin Oncol. 1990;8:396-401. 
2. Klasa RJ, Murray N, Coldman AJ. Dose-intensity meta-analysis of chemotherapy regimens in small cell carcinoma of the lung. J Clin Oncol. 1991;9:499-508.

3. Turrisi AT. Cisplatin-etoposide based chemoradiation treatment for limited small cell lung cancer: the current situation. Anticancer Res. 1994;14:289-294.

4. van Zandwijk N. Are we moving towards continuous treatment in small cell lung cancer (SCLC). Anticancer Res. 1994;14:309-312.

5. Wampler GL, Helm NM, Ellison NM, Ahlgren JD, Fryer JG. Comparison of cyclophosphamide, doxorubicin, and vincristine in the treatment of extensive-disease small cell lung carcinoma: a MidAtlantic Oncology Program Study. J Clin Oncol. 1991;9:1438-1445.

6. Maurer LH, Herndon JE II, Hollis DR, et al. Randomized trial of chemotherapy and radiation therapy with and without warfarin for limited-stage small cell lung cancer: a Cancer and Leukemia Group B study. J Clin Oncol. 1997;15:3378-3387.

7. Moro D. Small cell lung cancer: patients surviving longer than thirty months. Anticancer Res. 1994;14:301-304.

8. Cook RM, Miller YE, Bunn PA. Small cell lung cancer: etiology, biology, clinical features, staging, and treatment. Curr Probl Cancer. 1993; 17:71-141.

9. Sandler AB. Current management of small cell lung cancer. Semin Oncol. 1997;24:463-476.

10. Zangemeister-Wittke U, Stahel RA. Novel approaches to the treatment of small cell lung cancer. Cell Mol Life Sci. 1999;55:1585-1598.

11. Carpenter D. NMDA receptors and the molecular mechanisms of excitotoxicity. In: Johnson P, Boldyrev AA, editors. Oxidative Stress at the Molecular, Cellular, and Organ Levels, Trivandrum: Research Signpost. 2002. p. 77-88.

12. Hinoi T, Takarada T, Ueshima T, Tsuchihashi Y, Yoneda Y. Glutamate signaling in peripheral tissues. Eur J Biochem. 2004;271:1-13.

13. North WG, Fay MJ, Du JL, Cleary M, Gallagher JD, McCann FV. Presence of functional NMDA receptors in a human neuroblastoma cell-line. Mol Chem Neuropathol. 1997;30:77-94.

14. Sonkusare SK, Kaul CL, Ramarao P. Dementia of Alzheimer's disease and other neurodegenerative disorders-memantine, a new hope. Pharmacol Rev. 2005;51:1-17.

15. Plosker GL, Lyseng-Williamson KA. Memantine: a pharmacoeconomic review of its use in moderate-to-severe Alzheimer's disease. Pharmacoeconomics. 2005;23:193-206.

16. Kashiwagi K, Masuko T, Nguyen CD, et al. Channel blockers acting at N-methyl-D-aspartate receptors:differential effects of mutations in the vestibule and ion channel pore. Mol Pharmacol. 2002;61:533-545.

17. Fredriksson A, Danysz W, Quack G, Archer T. Co-administration of memantine and amantadine with sub/suprathreshold doses of L-dopa restores motor behaviour of MPTP-treated mice. J Neural Transm. 2001;108:167-187.

18. Friedmann AS, Malott KA, Memoli VA, Pai SI, Yu XM, North WG. Products of vasopressin gene expression in small-cell carcinoma of the lung. Br J Cancer. 1994;69:260-263.

19. Keegan BP, Memoli VA, North WG. Targeting the neurophysin-related cell surface.antigen on small cell cancer using a monoclonal antibody against the glycopeptide region (MAG-1) of provasopressin. Mol Cancer Ther. 2002;1:1153-1159.
20. Hess SD, Daggett LP, Crona J, et al. Cloning and functional characterisation of human heteromeric N-methyl-D-aspartate receptors. J Pharmacol Exper Therap. 1998;278:808-816.

21. Roos DH, Puntel RL, Santos MM, Souza DO, Farina M, Nogueira CW, et al. Guanosine and synthetic organoselenium compounds modulate methylmercury-induced oxidative stress in rat brain cortical slices: involvement of oxidative stress and glutamatergic system. Toxicol In Vitro. 2009;23:302-307.

22. Danilczuk Z, Ossowska G, Lupina T, Ciesslik K, Zebrowska-Lupina I. Effect of NMDA receptor antagonists on behavioral impairment induced by chronic treatment with dexamethasone. Pharmacol Rep. 2005;57:47-54.

23. Do Couto BR, Aguilar MA, Manzanedo C, Rodriguez-Arias M, Minarro J. Effects of NMDA receptor antagonists (MK801 and memantine) on the acquisition of morphine-induced conditioned place preference in mice. Prog NeuroPsychopharm Biol Psych. 2004;28:1035-1042.

24. Moriyoshi K, Masu M, Ishu T, Shigemoto R, Mizuno N, Nakanishi S. Molecular cloning and characterization of the rat NMDA receptor. Nature. 1991;354:31-37.

25. Longuemare MC, Keung EC, Chun S, Sharp FR, Chan PH, Swanson RA. MK801 reduces uptake and stimulates efflux of excitatory amino acids via membrane depolarization. Am J Physiol. 1996;270:C1398-C1404.

26. Stepulak A, Sifringer M, Wojciech R, et al. NMDA antagonist inhibits the extracellular signal-regulate pathway and suppresses cancer growth. Proc Natl Acad Sci. 2005;102:15605-15610.

27. North WG, Gao G, Memoli VA, Pang RHL, Lynch L. Breast cancer expresses functional NMDA receptors. Breast Cancer Res Treat. 2009. In press.

28. Tricklebank MD, Singh L, Oles RJ, Preston C, Iversen SD. The behavioural effects of MK-801: a comparison with antagonists acting non-competitively and competitively at the NMDA receptor. Eur $J$ Pharmacol. 1989;167:127-135.

29. Kawabe K, Yoshihara T, Ichitani Y, Iwasaki T. Intrahippocampal d-cycloserine improves MK-801-induced memory deficits: radial arm maze performance in rats. Brain Res. 1998;814:226-230.

30. Gilbert ME. The NMDA-receptor antagonist, MK-801, suppresses limbic kindling and kindled seizures. Brain Res. 1988;463:90-99.

31. During MJ, Symes CW, Lawlor PA, et al. An oral vaccine against NMDAR1 with efficacy in experimental stroke and epilepsy. Science. 2000;287:1453-1460.

32. Reynolds IJ, Miller RJ. Ifenprodil is a novel type of N-methyl-Daspartate receptor antagonist: interaction with polyamines. Mol Pharmacol. 1989;36:758-765.

33. Williams K. Ifenprodil discriminates subtypes of N-methyl-aspartate receptor: selectivity and mechanisms at recombinant heteromeric receptors. Mol Pharmacol. 1993;44:851-859.

34. Gallagher MJ, Huang H, Pritchett DB, Lynch DR. Interactions between Ifenprodil and the NR2B subunit of the N-methyl-D-aspartate receptor. J Biol Chem. 1996;271:9603-9611.

35. Malinowska B, Napiórkowska-Pawlak D, Pawlak R, Buczko W, Göthert M. Ifenprodil influences changes in mouse behaviour related to acute and chronic ethanol administration. Eur J Pharmacol. 1999;377:13-19.
Clinical Pharmacology: Advances and Applications

\section{Publish your work in this journal}

Clinical Pharmacology: Advances and Applications is an international, peer-reviewed, open access journal publishing original research, reports, reviews and commentaries on all areas of drug experience in humans. The manuscript management system is completely online and includes a very quick and fair peer-review system, which is all easy to use.

\section{Dovepress}

Visit http://www.dovepress.com/testimonials.php to read real quotes from published authors. 